Article

\title{
Impact of the Built Environment and Bicycling Psychological Factors on the Acceptable Bicycling Distance of Rural Residents
}

\author{
Yan Wang ${ }^{1}$, Yibin Ao ${ }^{2, *}$, Yuting Zhang ${ }^{2}$, Yan Liu ${ }^{3}$, Lei Zhao ${ }^{2}$ and Yunfeng Chen ${ }^{4}$ \\ 1 Department of Engineering Management, Sichuan College of Architectural Technology, Deyang 618000, \\ China \\ 2 College of Environment and Civil Engineering, Chengdu University of Technology, Chengdu 610059, China \\ 3 School of Public Affairs and Administration, University of Electronic Science and Technology of China, \\ Chengdu 611731, China \\ 4 School of Construction Management Technology, Purdue Polytechnic Institute, Purdue University, \\ West Lafayette, IN 47907, USA \\ * Correspondence: aoyibin10@mail.cdut.edu.cn
}

Received: 8 July 2019; Accepted: 12 August 2019; Published: 14 August 2019

\begin{abstract}
The ability to understand bicycling behavior in China's rural areas is critical in constructing an improved, sustainable, countryside amid the rapid urbanization in the country. This study analyzes the influence of individual bicycling psychology, objective, and perceived built environment on the acceptable bicycling distance of rural residents. This research is conducted by controlling for the socio-demographic characteristics of the residents on the bases of a face-to-face questionnaire survey and an on-site measurement. Exploratory factor analysis shows three attitudinal common factors on bicycling infrastructure, namely, bicycling ancillary facilities, bicycle lane conditions, and safety, and two bicycling motivation factors, namely, convenience and other motivations. Multiple linear regression was estimated and results of the models were consistent. Individual bicycling psychology and built environment factors significantly influence the acceptable bicycling distance of rural residents. The socio-demographic variables insignificantly influence the acceptable bicycling distance, which is inconsistent with the existing literature. The research results provide a broad empirical base for the complex relationships among individual bicycling psychological factors, objective and perceived built environment, and bicycling behavior. This study presents the first research on bicycling in Chinese rural areas and provides guidance for the development of effective countermeasures in constructing ecovillages.
\end{abstract}

Keywords: rural built environment; bicycling distance; bicycling psychological factors; bicycling behavior; multiple linear regression model

\section{Introduction}

Cities worldwide promote the use of bicycles for transportation to achieve physical and mental health, zero emission, and space saving [1]. Bicycling is a healthy mode of transportation that promotes physical activity, the health benefits of which have been widely recognized [2,3]. Extensive evidence suggests that physical activity reduces the risk of cardiovascular diseases, diabetes, and colon, breast, and endometrial cancer [4,5]. Bicycling can also enhance aerobic lung function and has been proven to be able to facilitate the achievement of the recommended lung function levels [6-8]. Furthermore, regular bicycling can improve the personal health of residents by reducing their sedentary lifestyle $[9,10]$. Bicycle riding is likewise considered environmentally sustainable compared with motor vehicle travel because of low-energy consumption and zero emission of pollutants [11]. Therefore, 
the use of bicycles can reduce air and noise pollution [12]. This implication is crucial for the future transition to a sustainable city. Evidently, promoting active transportation through bicycling and walking is recognized as being among the effective methods to build an environment-friendly and healthy city $[13,14]$. In the past two decades, cities and metropolitan areas in the US have used a significant proportion of their federal funds to improve their respective bicycling systems [15]. Moreover, bicycles offer a variety of commuting benefits, including economy, reliability, and speed, thereby making bicycles a suitable vehicle for travel in many cities and suburbs $[16,17]$. However, empirical evidence remains limited despite the expanding interest in linking the built environment of transportation and health sciences with bicycling [18-20].

Bicycling is a sustainable transportation mode that promotes physical and mental health. However, rapid rural urbanization in China has resulted in the annual decline in the number of bicycles per 100 rural households in the country, whereas the number of cars has been increasing during the same period (see Figure 1) [21]. Rural China remains in the process of continuous construction, which potentially leads to minimal use of bicycles. Hence, the demand of rural residents for bicycling facilities should be explored and psychological factors, such as attitude, preference, motivation, and purpose of bicycling, should be studied. These factors are conducive to ecological rural planning and can effectively encourage rural residents to have low-carbon and healthy travel. The current study attempts to fill in this gap in the literature, explore the impact of the rural built environment and the psychological determinants of rural residents on the acceptable bicycling distance, and provide scientific theoretical guidance to further plan and develop ecovillages.

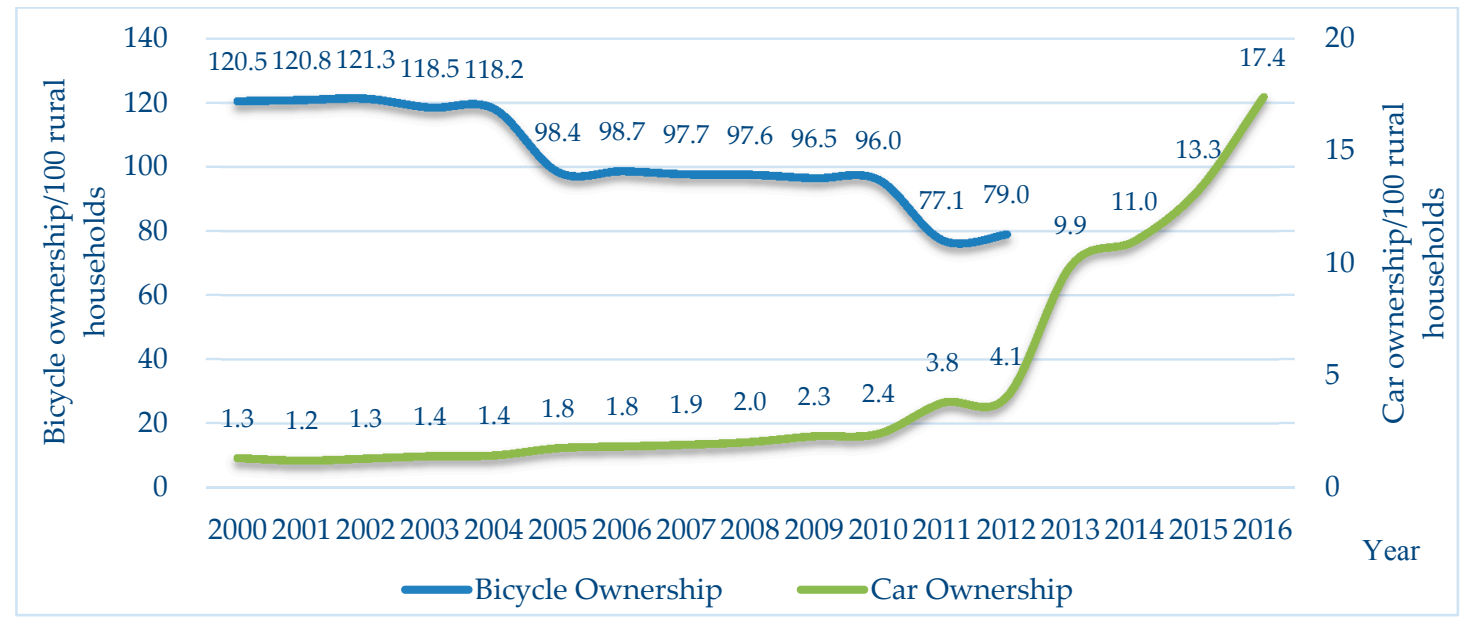

Figure 1. Household car and bicycle ownerships in rural China. Note: The data of bicycle ownership is from the Statistical Yearbook of China, but since the statistical yearbook of 2013, bicycle ownership has not been counted. Therefore, the bicycle ownership plot stops after the year 2012.

The remainder of this paper is organized as follows. Section 2 discusses the existing literature on the influencing factors of bicycling behavior. Section 3 presents the materials and method used in the current study. This section also describes the data collection and variable and model specifications. Section 4 discusses the results of the proposed model. Section 5 presents the strengths and limitations of this study. Lastly, Section 6 presents the conclusion and policy implications.

\section{Literature Review}

Numerous factors affect people's decision to ride a bicycle, including the traffic volume of motor vehicles $[8,22,23]$, safe and reliable bicycling infrastructure [24,25], and socio-demographic characteristics [26,27]. An increasing number of studies have considered the impact of psychological determinants on bicycling [28-30]. Moreover, such natural factors as landscape, weather, and terrain may determine the decision of a person to ride a bicycle [31]. Hence, the built environment, individual 
bicycling psychology, and socio-demographic characteristics are the three main factors affecting bicycling behavior [32,33].

\subsection{Built Environment Factors}

Various studies have demonstrated the impact of the built environment attributes on bicycling behavior, including the impact of land use density and diversity, street connectivity, and distance between departure and destination. Intensive residential areas [34] and mixed land use [35] reduce travel distance and increase the proportion of bicycling transportation. By contrast, heavy traffic volume [36] and increase in travel distance [31,36] are negatively correlated with bicycling trips. Bicycle lane density, street connectivity, and infrastructure accessibility are positively correlated with commuter bicycling frequency [2,37]. Bicycle parking and destination facilities, such as shower and changing rooms, are positively correlated with bicycling frequency [38]. The connectivity of transportation network, particularly bicycle road infrastructure, traffic flow and speed, and road surface quality and grade, are correlated with the use of bicycles $[33,39]$. Research has also shown that cyclists considerably focus on bicycling facilities [36,40]. Dedicated bicycle lanes and destination facilities for bicycling can encourage people to ride bicycles [41]. Recent studies have suggested that, wherever possible, the measurement data for objective and subjective built environments should be included because different correlations exist between the objective and perceived built environment for the same environmental attributes [42-45]. Objective measures are often derived (using geographic information systems) from systematic observations, audits, and calculations based on existing spatial data (e.g., street networks and land use data). By contrast, subjective measures are often derived from self-reported data, thereby reflecting the subjectiveness of the respondents on an environment [46]. Different people may have varying perceptions of the same built environment, thereby prompting them to behave differently [47]. For example, perceived traffic safety is different from the objective measures of traffic safety, although both aspects will affect the decision to bike [48]. The impact of the built environment on bicycling behavior has attracted the attention of many scholars, although the theoretical debate has never stopped. After considering individual bicycling psychology, the influence of the built environment on bicycling behavior will become substantially complicated.

\subsection{Psychological Factors of Bicycling}

Many people continue to choose not to ride a bicycle, even though the supportive bicycling infrastructure is enhancing the opportunities for and safety of bicycling. Frequently, a good bicycling infrastructure is not necessary. Despite the lack of good bicycling facilities, some people continue to ride bicycles regularly just because they like bicycling [11]. Accordingly, people's preference for bicycling is an important predictor of whether they ride bicycles. Hence, individual bicycling psychological factors are crucial in analyzing bicycling behavior [28-30]. The attitude toward the benefits of bicycling directly affects bicycling behavior. Personal attitudes include the preference for biking activities and perceived physical and mental health benefits of bicycling, which are highly relevant to this activity [32,49]. Hence, liking bicycling is the most important factor in explaining the ownership and regular use of bicycles, given the good bicycling infrastructure [49]. A few studies have shown that liking bicycling is also closely related to bicycling distance and the decision to use bicycles [49,50]. These findings suggest that the role of bicycling psychology can no longer be disregarded. Furthermore, additional empirical research should be conducted to confirm whether our understanding of attitudes is consistent with that in various studies and to formulate effective policies that will encourage residents to ride bicycles. For example, many cities in the Netherlands, Denmark, and Germany plan to stimulate bicycling interest and enthusiasm for people of all age groups [34]. Therefore, individual psychological determinants, such as attitude, perception, and preference of cyclists, are important in explaining bicycling behavior. The majority of the related studies have shown that even after controlling for the statistically significant effects of individual bicycling psychological factors, the impact of the built 
environment factors remains statistically significant, thereby complicating the influence of the built environment on travel behavior [51-53].

\subsection{Socio-Demographic Factors}

Socio-demographic characteristics significantly impact the bicycling behavior of residents. Gender and income are the two demographic factors that substantially affect bicycling behavior in the majority of the research conducted. In particular, women are concerned with motor vehicles [26,27]. Among commuter cyclists, women prefer to ride away from motorized lanes [54]. Therefore, improving bicycle lanes, lane forms, and bicycle facilities significantly increases separation from motor vehicles, thereby possibly increasing the bicycling activities of women [55]. Gender also affects the perception of bicycling risk and behavior selection. One study has determined that $65 \%$ of male cyclists will continue to opt for riding bicycles even if they perceive the bicycling risks, whereas only $50 \%$ of women will continue to ride bicycles under the same bicycling risk perception [56]. Income has a decisive role in the choice of transportation mode. People who do not own a car are likely to walk or bike [57]. Thus, bicycle users constitute the majority of the households with annual income below USD 50,000 [58]. However, voluntary and involuntary bicycling should be distinguished from each other [59]. Many high-income cyclists voluntarily choose bicycling as a form of entertainment, exercise, and other personal purposes. Therefore, the individual psychological determinants of cyclists influence bicycling behavior after controlling for the socio-demographic variables [60].

Recent studies on bicycling behavior have focused on bicycling mode choice, route selection [32,33], and exploration of the factors that affect bicycling frequency [2,12]. However, only a few studies have focused on bicycling distance. Meanwhile, empirical studies have mainly concentrated on cities and disregarded the rural areas, particularly in China. Hence, the findings of this literature review justify the importance of exploring the impact of key factors, such as bicycling psychology, on the acceptable bicycling distance of rural residents in China.

\section{Materials and Method}

\subsection{Model Settings}

Exploratory factor analysis (EFA) is first deployed to identify important broad attitude on bicycling condition and bicycling motivation. Two models are adopted in this study to observe the stability of the relationship between the independent and dependent variables. The EFA results will be used in linear regression to explore the influence of bicycling psychological factors and built environment on acceptable bicycling distance of rural residents.

The multiple linear regression model will be used to study the relationship between the dependent variable and at least one independent variable [61]. The general form of the linear regression model can be written as follows:

$$
y=x_{1} \beta_{1}+x_{2} \beta_{2}+\cdots+x_{n} \beta_{n}+\varepsilon=x_{i}^{\prime} \beta_{i}+\varepsilon,
$$

where, $y$ refers to the vector of the dependent variables, which is the acceptable bicycling distance that the respondents filled in, thereby making $y$ a continuous variable, $x_{i}$ refers to the vector of the independent variables and mainly refers to the psychological factors and built environment, and $\varepsilon$ is the vector of the errors in the equation.

\subsection{Data Collection and Descriptive Analysis}

The sample villages were selected from the rural Sichuan Province for its immense economic output and rapid urbanization. The economic aggregate of the Sichuan Province ranks second in Central and Western China and first in Western China with a per capita GDP (Gross Domestic Product) of 44,651 Yuan. At the end of 2018, the number of permanent residents in the Sichuan Province was 83.41 million 
and the registered population was 91.218 million. The urbanization rates involving the permanent residents and registered population were $52.29 \%$ and $35.87 \%$, respectively. Accordingly, considerable changes in rural household vehicle ownership have occurred because of rapid urbanization. For example, the car ownership rates of rural households were $12.5 \%$ and $1.0 \%$ by the end of 2016 and 2000, respectively. However, the bicycle ownership rate declined rapidly (National Bureau of Statistics of the People's Republic of China) [21] (Figure 2). Travel behavior would change owing to substantial changes in rural household vehicle ownership. Therefore, an empirical study should be conducted in rural Sichuan for rural revitalization and new rural construction.

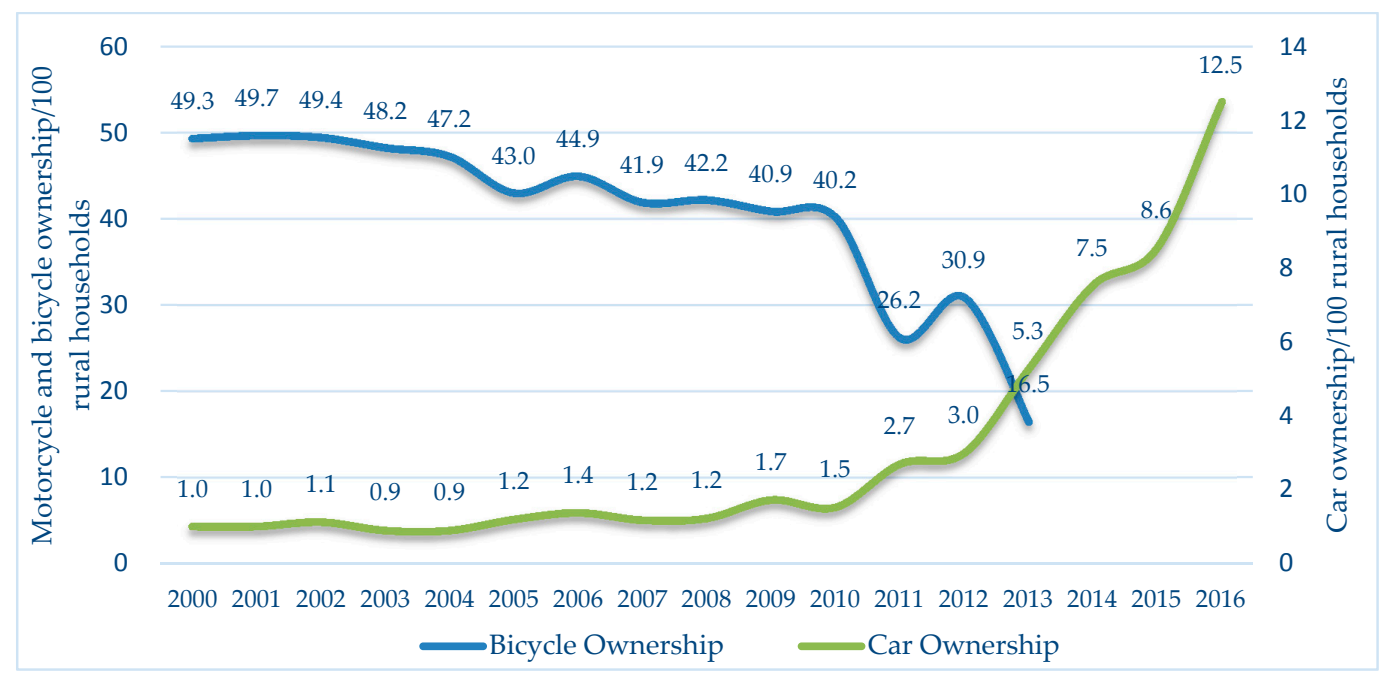

Figure 2. Household car and bicycle ownerships in rural Sichuan. Note: The data of bicycle ownership is from the Statistical Yearbook of China, but since the statistical yearbook of 2014, bicycle ownership has not been counted. Therefore, the bicycle ownership plot stops after the year 2013.

This study selected seven villages: three new concentrated villages and four traditional scattered villages. Additional details of the sample and data collection for this study are included in the current authors' previous research $[62,63]$. Eventually, we prepared 374 valid rural household questionnaires for this study. Table 1 shows the socio-demographic attributes of the rural respondents. Figure 3 presents the map of the study area's location and sample village location.

Table 1. Socio-demographic attributes of the rural respondents.

\begin{tabular}{cccc}
\hline Variable & Level & Number of Sample & Percent (\%) \\
\hline \multirow{2}{*}{ Male } & 0 for female & 226 & 60.43 \\
& 1 for male & 148 & 39.57 \\
Age & 1 represent age 16-25 & 47 & 12.57 \\
& 2 represent age 25-40 & 65 & 17.38 \\
& 3 represent age 41-50 & 112 & 29.95 \\
4 represent age 51-60 & 80 & 21.39 \\
& 4 represent age 61-70 & 70 & 18.72 \\
Income & 1 represents 0 & 116 & 31.02 \\
& 2 represents 0-5 thousand yuan & 38 & 10.16 \\
& 3 represents 5-10 thousand yuan & 80 & 21.39 \\
& 4 represents 10-20 thousand yuan & 60 & 16.04 \\
5 represents 20-40 thousand yuan & 59 & 15.78 \\
Acceptable bicycling & 6 represents $>40$ thousand yuan & 21 & 5.61 \\
distance (KM) & $(0,1)$ & 65 & 17.38 \\
& $(1,2)$ & 108 & 28.88 \\
& $(2,3)$ & 88 & 23.53 \\
& $(3,4)$ & 44 & 11.76 \\
& $(4,5)$ & 56 & 3.97 \\
\hline
\end{tabular}




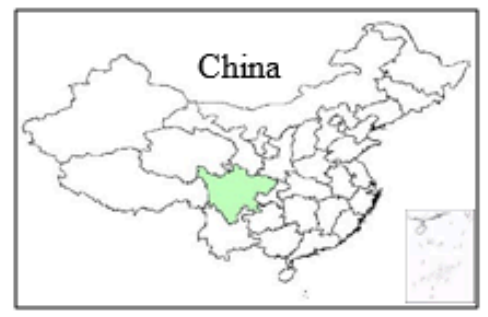

Study Area Location
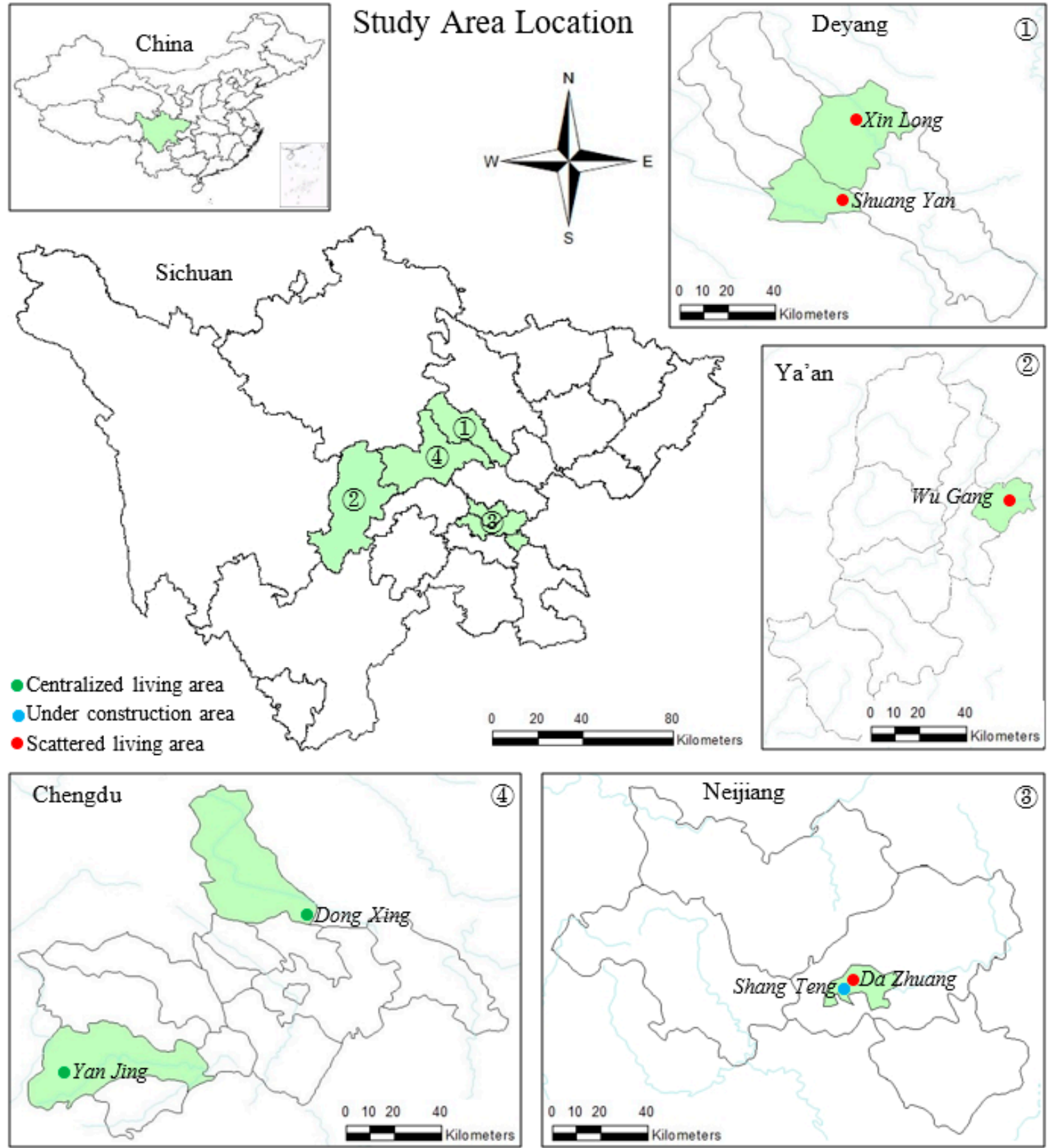

Figure 3. Map of the study area's location and the sample village location. Note: The map is from the National Bureau of Surveying, Mapping, and Geographic Information.

Apart from conducting a household survey, we also measured the actual built environment basic data on-site, further details of which are included in the current authors' previous research $[62,63]$. Table 2 shows the basic data of the actual built environment that were measured on-site. 
Table 2. Basic data of the actual built environment.

\begin{tabular}{cccccc}
\hline $\begin{array}{c}\text { Name of } \\
\text { Villages }\end{array}$ & $\begin{array}{c}\text { Valid Sample } \\
\text { Number }\end{array}$ & $\begin{array}{c}\text { Distance to } \\
\text { Nearest } \\
\text { Hospital (KM) }\end{array}$ & $\begin{array}{c}\text { Distance to } \\
\text { Nearest } \\
\text { Market (KM) }\end{array}$ & $\begin{array}{c}\text { Distance to } \\
\text { Nearest School } \\
\text { (KM) }\end{array}$ & $\begin{array}{c}\text { Distance to } \\
\text { Nearest Public } \\
\text { Transportation } \\
\text { Station (KM) }\end{array}$ \\
\hline $\begin{array}{c}\text { Dazhuang } \\
\text { Wugang }\end{array}$ & 57 & 0.05 & 3.00 & 0.50 & 2.50 \\
Shuangyan & 56 & 0.20 & 3.50 & 2.50 & 0.2 \\
Xinlong & 61 & 0.60 & 1.60 & 1.60 & 0.50 \\
Doxing & 58 & 4.90 & 0.80 & 3.00 & 1.20 \\
Shangteng & 49 & 0.00 & 0.00 & 1.50 & 0.69 \\
Yanjing & 40 & 1.60 & 1.50 & 0.50 & 0.50 \\
\hline
\end{tabular}

\subsection{Variable Settings}

\subsubsection{Socio-Demographic Variables}

The literature review shows that socio-demographic factors significantly influence travel behavior, such as acceptable bicycling distance. Accordingly, this study selects basic such socio-demographic information as (1) gender, (2) age, and (3) income.

\subsubsection{Psychological Variables of Bicycling}

Four types of psychological variables of bicycling were mainly considered to explore the effects of the psychological factors of bicycling on the acceptable bicycling distance for individuals $[12,49,50]$.

(1) Attitude on bicycling infrastructures. The respondents were asked to evaluate 13 statements using a 5-point Likert scale that ranges from 1 (i.e., strongly negative to ride bicycles) to 5 (i.e., strongly positive to ride bicycles) for the following question: Are you willing to ride bicycles when the following conditions are satisfied?

(2) Bicycling motivation. The respondents were asked to evaluate eight statements using a 5-point Likert scale that ranges from 1 (i.e., strongly disagree) to 5 (i.e., strongly agree) for bicycling motivation.

EFA was performed using SPSS 23.0 to identify the latent structures underlying the aforementioned attitude and motivation response. Three common factors of attitude on bicycling infrastructure conditions and two common factors of bicycling motivation were eventually obtained. The common factors will enter the multivariate models.

(3) Bicycling purpose. The respondents were asked to select their bicycling purpose if they want to ride bicycles from the given seven options. The seven bicycling purposes were transferred to seven binary variables $(1=$ yes, $0=$ no).

(4) Riding preference. To accurately collect riding preference data, the respondents were asked to rank car, public transportation, motorcycle, bicycle, and electric bicycle on the basis of their preferences. The scale ranges from 5 (i.e., most favorite travel mode) to 1 (i.e., least favorite travel mode). Lastly, bicycle, motorcycle, and electric bicycle were selected as the riding preference variables using the given numbers (1-5).

\subsubsection{Built Environment Variables}

This study focuses on the objective and perceived built environment information on the bases of the on-site measurement of the built environment and perceived data of the respondents. Moreover, this research mainly considers four destinations to explore the connection between the objective and perceived built environment. All destinations are in the most acceptable bicycling distance scope (i.e., $5 \mathrm{~km}$ ) (see Figure 4). First, objective built environment indicators were measured on-site using the Baidu navigation app (see Table 3). Second, the respondents were asked to assess the four statements using a 5-point Likert scale that ranges from 1 (strongly disagree) to 5 (strongly agree) to measure the perceived built environment indicators (see Table 3). 


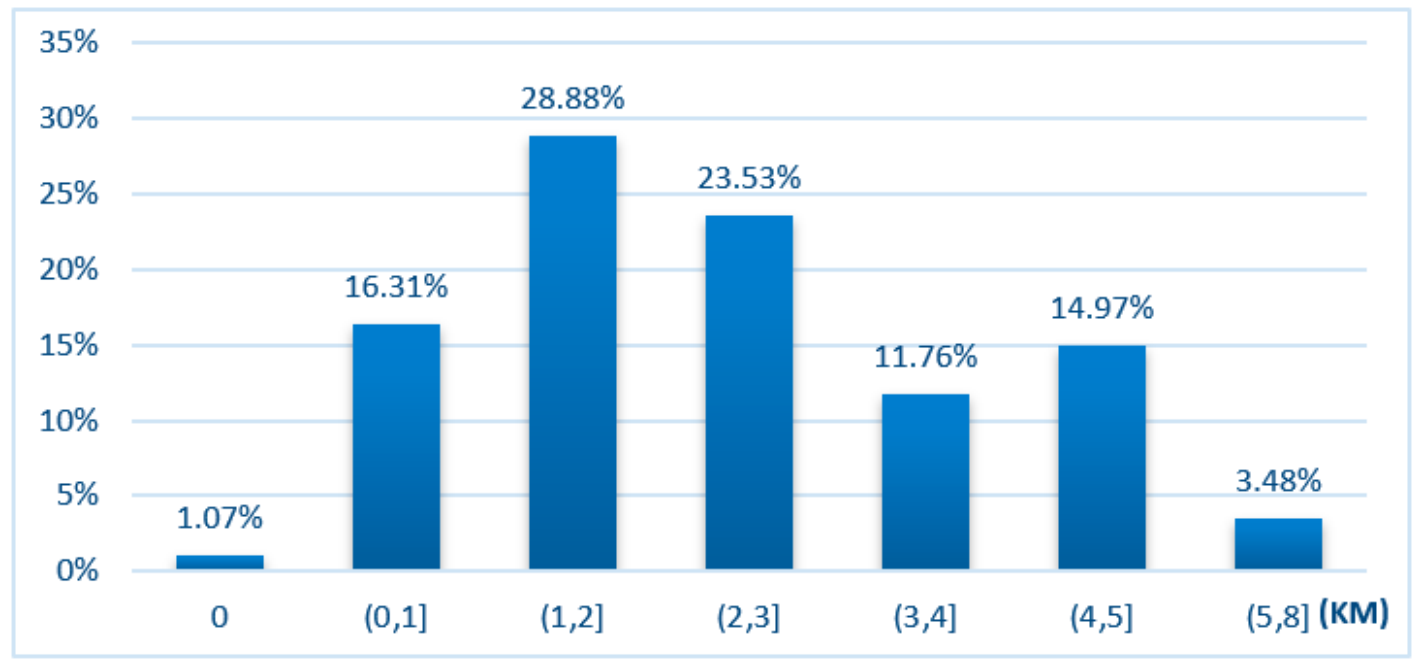

Figure 4. Acceptable bicycling distances of the rural residents of Sichuan.

Table 3. Objective and perceived built environment variables.

\begin{tabular}{ccc}
\hline & Objective Built Environment Indicators & Perceived Built Environment Indicators \\
\hline 1 & Distance to nearest hospital from village center. (O_H) & It is very convenient to hospital. (P_H) \\
2 & Distance to nearest market from village center. (O_M) & It is very convenient to market. (P_M) \\
3 & Distance to nearest school from village center. (O_S) & It is very convenient to school. (P_S) \\
4 & Distance to nearest public transportation station from & It is very convenient to public \\
& village center. (O_P) & transportation station. (P_P) \\
\hline
\end{tabular}

\subsubsection{Dependent Variable}

The acceptable bicycling distance of rural residents is the dependent variable in this study. The respondents were asked to indicate the bicycling distance that is acceptable to them. The preliminary statistical analysis indicated that the maximum, minimum, and average acceptable bicycling distances are 8,0 , and $2.873 \mathrm{~km}$, respectively (see Table 3). The dependent variable was dealt with in two ways to accurately analyze the influence of the independent variables on the dependent variable. First, the acceptable bicycling distance data filled out by the respondents is retained because it is a continuous variable. In particular, the data were entered into the multiple linear regression model as a continuous dependent variable. Second, an ordered variable was processed using serial numbers to indicate the acceptable bicycling distance of the respondents. The data processing was as follows: 0 represents $0 \mathrm{~km}$, 1 represents an acceptable bicycling distance of over $0 \mathrm{~km}$ and below or equal to $1 \mathrm{~km}, 2$ represents the distance above $1 \mathrm{~km}$ and below or equal to $2 \mathrm{~km}, 3$ represents the distance above $2 \mathrm{~km}$ and below or equal to $3 \mathrm{~km}$, and so on. Lastly, 6 represents distance above $5 \mathrm{~km}$ and below or equal to $8 \mathrm{~km}$. Figure 4 shows the frequency statistics of the ordered variable. The most number of people who can accept a bicycling distance above $1 \mathrm{~km}$ and below $2 \mathrm{~km}$ reached $28.88 \%$, followed by over $2 \mathrm{~km}$ and below or equal to $3 \mathrm{~km}$. Over $50 \%$ of the respondents believe that bicycling distance above $1 \mathrm{~km}$ and below or equal to $3 \mathrm{~km}$ is acceptable. Table 4 shows all the variables. The variance inflation factor (VIF) test indicates that this study has no multicollinearity problem. 
Table 4. Descriptive statistical summary of the variables used in this study.

\begin{tabular}{|c|c|c|c|c|c|c|}
\hline Variables & Mean & S.D & Minimum & Maximum & Type & VIF \\
\hline \multicolumn{7}{|c|}{ Dependent Variables } \\
\hline $\begin{array}{l}\text { Acceptable Bicycling } \\
\text { Distance }(\mathrm{km})\end{array}$ & 2.874 & 1.433 & 0.000 & 6.000 & Ordinal $(0,1,2,3,4,5,6)$ & - \\
\hline $\begin{array}{l}\text { Acceptable Bicycling Distance } \\
\text { of the Original Data }(\mathrm{km})\end{array}$ & 2.873 & 1.542 & 0.000 & 8.000 & Continuous & - \\
\hline \multicolumn{7}{|c|}{ Independent Variables } \\
\hline Male & 0.396 & 0.489 & 0.000 & 1.000 & Binary: 0-female/1-male & 1.257 \\
\hline Age & 3.163 & 1.270 & 1.000 & 5.000 & Nominal (5 levels) & 1.273 \\
\hline Income & 1.407 & 1.730 & 0.000 & 15.000 & Continuous & 1.374 \\
\hline Cycling ancillary facilities & 0.000 & 0.999 & $(4.018)$ & 4.177 & Common factor & 1.193 \\
\hline Bicycle lane conditions & 0.000 & 0.999 & $(2.752)$ & 3.383 & Common factor & 1.172 \\
\hline Safety & 0.000 & 0.999 & (3.554) & 3.885 & Common factor & 1.200 \\
\hline Other motivations & 0.000 & 0.999 & $(2.922)$ & 2.233 & Common factor & 1.405 \\
\hline Convenient & 0.000 & 0.999 & (3.058) & 2.104 & Common factor & 1.216 \\
\hline Physical activity & 0.489 & 0.500 & 0.000 & 1.000 & Binary: 0-no/1-yes & 1.390 \\
\hline Go to work/school & 0.160 & 0.367 & 0.000 & 1.000 & Binary: 0-no/1-yes & 1.155 \\
\hline Bike with children & 0.147 & 0.354 & 0.000 & 1.000 & Binary: 0-no/1-yes & 1.209 \\
\hline Go shopping & 0.340 & 0.474 & 0.000 & 1.000 & Binary: 0-no/1-yes & 1.537 \\
\hline Visit friends & 0.267 & 0.443 & 0.000 & 1.000 & Binary: 0-no/1-yes & 1.308 \\
\hline To entertainment & 0.112 & 0.316 & 0.000 & 1.000 & Binary: 0-no/1-yes & 1.174 \\
\hline Others & 0.134 & 0.340 & 0.000 & 1.000 & Binary: 0-no/1-yes & 1.168 \\
\hline Liking riding motorcycles & 2.631 & 1.258 & 1.000 & 5.000 & Ordinal & 1.441 \\
\hline Liking riding electric bicycles & 3.393 & 1.123 & 1.000 & 5.000 & Ordinal & 1.164 \\
\hline Liking bicycling & 2.693 & 1.350 & 1.000 & 5.000 & Ordinal & 1.395 \\
\hline O_P (see Table 3) & 1.426 & 1.282 & 0.200 & 3.900 & Continuous & 2.445 \\
\hline O_M (see Table 3) & 1.695 & 1.155 & 0.000 & 3.500 & Continuous & 2.967 \\
\hline O_S (see Table 3) & 1.742 & 0.880 & 0.500 & 3.000 & Continuous & 1.688 \\
\hline O_H (see Table 3) & 1.313 & 1.702 & 0.000 & 4.900 & Continuous & 2.706 \\
\hline P_S (see Table 3) & 3.439 & 0.971 & 1.000 & 5.000 & Ordinal & 2.906 \\
\hline P_M (see Table 3) & 3.508 & 0.939 & 1.000 & 5.000 & Ordinal & 3.810 \\
\hline P_P (see Table 3) & 3.179 & 1.118 & 1.000 & 5.000 & Ordinal & 2.204 \\
\hline P_H (see Table 3) & 3.634 & 0.839 & 1.000 & 5.000 & Ordinal & 1.498 \\
\hline
\end{tabular}

\section{Results and Discussion}

This section presents the results of the analysis. First, we present the descriptive statistics for bicycling psychology, including the stated bicycling purpose, motivation, attitudes on bicycling infrastructure conditions, preferences for bicycling, riding motorcycles, and riding electric bicycles. Thereafter, the current section provides the EFA results of the latent attitude and motivation and the multiple linear regression of the acceptable bicycling distance.

\subsection{Attitude on Bicycling Infrastructure Conditions of the Rural Residents of Sichuan}

Figure 5 shows the results of the questionnaire survey on attitude. Over half of the respondents believe that every bicycle infrastructure condition (except shower facilities at the destination) encourages them to ride a bicycle. Over $70 \%$ of the respondents agree that these bicycling infrastructures, such as good-quality route surface, bicycle lanes separated from motor vehicle lanes, safety of bicycle lanes, and sufficiently wide bicycle path, encourage them to ride bicycles. Therefore, the good conditions of bicycle lanes have the most evident positive impact on bicycling for the current rural residents of Sichuan, followed by other ancillary facilities, such as bicycle parking, traffic lights, shade, and shower facilities. These statistical results are consistent with the actual situation in Sichuan without efficient specialized bicycle infrastructure. 


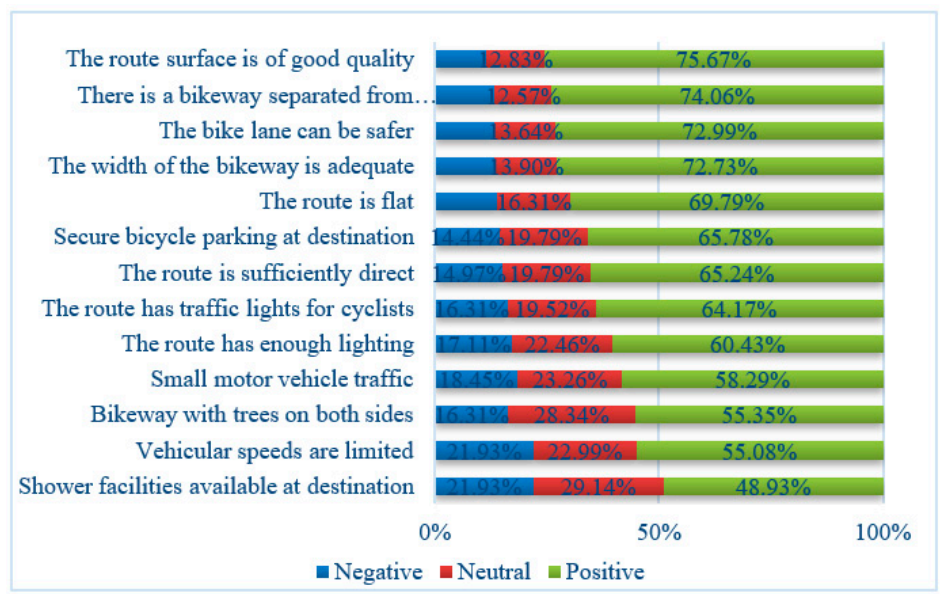

Figure 5. Attitude on bicycling infrastructure conditions for rural residents.

\subsection{Bicycling Motivation of the Rural Residents of Sichuan}

Figure 6 shows the preliminary statistics. A total of $83.42 \%$ of the respondents believe that bicycling is beneficial for physical and mental health, although an only few of them selected physical activity as their bicycling purpose. Over $75 \%$ of the respondents believe that bicycling is beneficial to the environment, bicycle parking, and money saving. Over $60 \%$ of the respondents believe that bicycling can ease traffic congestion and is also interesting. A total of $34.22 \%$ of the respondents disagree with the idea that "bicycling is fast," $34.22 \%$ of them agree with such statement. The respondents believe that bicycling does not have a fast advantage in speed compared with other bicycling motivations [12].

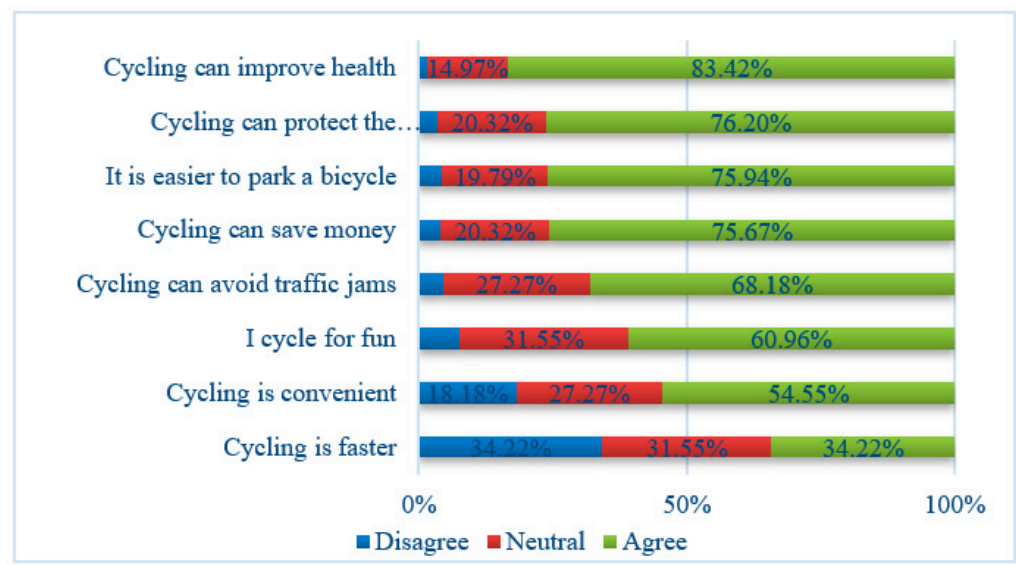

Figure 6. Bicycling motivations of the rural residents of Sichuan.

\subsection{Bicycling Purpose of the Rural Residents of Sichuan}

Figure 7 shows the distribution of the bicycling purpose of the rural residents based on the preliminary statistics. A total of $46.26 \%, 33.96 \%$, and $27.27 \%$ of the respondents selected going shopping, visiting friends, and going to work and school, respectively. Only $10.70 \%$ and $13.64 \%$ of the respondents selected physical activity and recreation options respectively, as bicycling purposes. These two options have the lowest selection rates. This finding is inconsistent with that of Fu and Farber [12], who conducted an investigation in Salt Lake City and found that bicycling is mainly a physical and recreational means of traveling for residents of this city. This finding shows a certain gap in the living conditions of residents between China and developed Western countries between urban and rural areas in China. These developments are consistent with the current situation in rural China. 


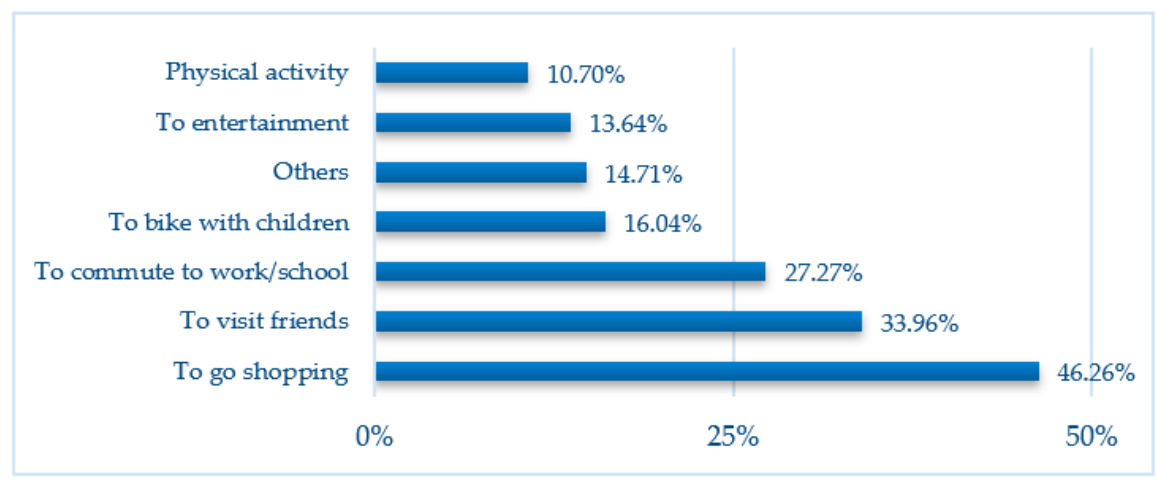

Figure 7. Bicycling purposes of the rural residents of Sichuan.

\subsection{Preferences for Riding Bicycles, Motorcycles, and Electric Bicycles}

Figure 8 shows the statistical results of the respondents' travel model preference. Their preference for public transportation and private cars is relatively more dispersed compared with their riding preferences. A total of $27.27 \%$ of the respondents expressed that they prefer bicycling, whereas $48.93 \%$ do not like bicycling. However, preference for electric bicycles is evidently higher than that of bicycles. A total of $46.79 \%$ of the respondents said that they prefer electric bicycles, whereas only $22.46 \%$ did not prefer this mode of transportation. The respondents' preference for motorcycles is more consistent than that for bicycles. This study mainly considers the influence of the riding preferences of rural residents on the acceptable riding distance. Therefore, the current research eventually chooses the preference data of bicycles, motorcycles, and electric bicycles to enter the multivariate models.

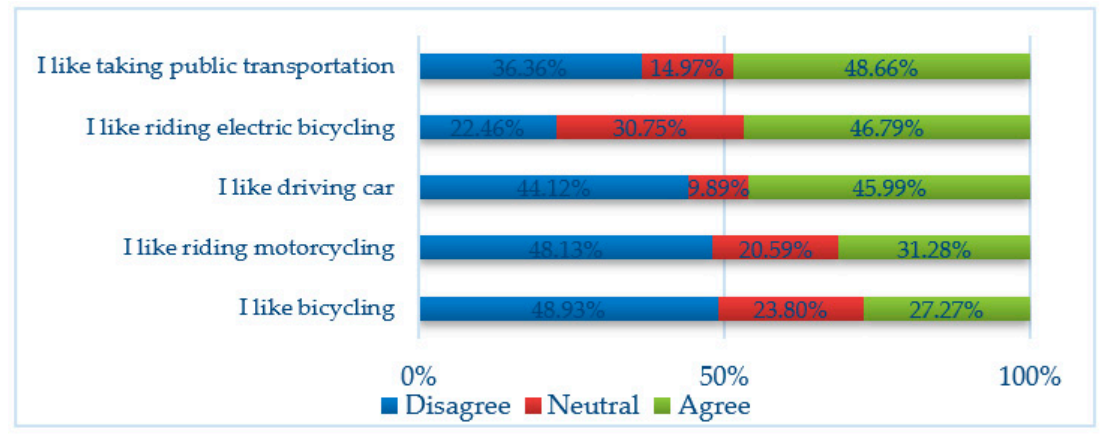

Figure 8. Travel mode preferences of the rural residents of Sichuan.

\subsection{Analysis of the Exploratory Factor Analysis (EFA) Results}

The Kaiser-Meyer-Olkin (KMO) and Bartlett's tests were used to investigate the factorability of individual attitudes to bicycling infrastructure conditions and bicycling motivation variables. The values for the KMO and Bartlett's tests were 0.956 and 0.809 respectively, thereby indicating that the data are suitable for EFA. Tables 5 and 6 list the items.

EFA identifies three common factors for the attitude to bicycling conditions. The identified factors explain $79.196 \%$ of the variance, while the number of factors is reduced from 13 to 3 . EFA also identifies two bicycling motivation factors, which explain $59.445 \%$ of the variance, while the number of factors is reduced from 8 to 2 . Therefore, the EFA results indicate that the number of variables reduced is considerably less than the information loss. Accordingly, the common factors of "bicycling condition attitude" and "bicycling motivation" can be interpreted and represented. Thereafter, the extracted components can be used in the linear regression and can effectively represent the bicycling condition attitude and bicycling motivation of the respondents. 
Table 5. Exploratory factor analysis (EFA) results of attitude on bicycling condition.

\begin{tabular}{cccc}
\hline \multirow{2}{*}{ The Items of Attitude on Bicycling Condition } & \multicolumn{2}{c}{ Component } \\
\cline { 2 - 4 } & Cycling Ancillary Facilities & Bicycle Lane Conditions & Safety \\
\hline The route has traffic lights for cyclists & 0.793 & \\
Shower facilities available at destination & 0.704 & 0.625 \\
Vehicular speeds are limited & 0.633 & 0.591 & \\
The bike lane can be safer & 0.632 & 0.600 \\
The route has enough lighting & 0.630 & 0.556 \\
The route is flat & 0.608 & 0.828 \\
Bikeway with trees on both sides & 0.592 & 0.790 & 0.780 \\
The width of the bikeway is adequate & & & 0.766 \\
The route surface is of good quality & & & 0.623 \\
The route is sufficiently direct & & & 0.618 \\
Small motor vehicle traffic & 0.582 & $29.686 \%$ & $19.385 \%$ \\
Secure bicycle parking at destination & $30.125 \%$ & $59.811 \%$ & $7.196 \%$ \\
There is a bikeway separated from traffic & $30.125 \%$ & 3.859 & 2.520 \\
\% of Variance & 3.916 & & \\
Cumulative & & & \\
Eigenvalues & & & \\
\hline
\end{tabular}

Extraction Method: Principal Component Analysis. Rotation Method: Varimax with Kaiser Normalization.

Table 6. EFA result of bicycling motivation.

\begin{tabular}{ccc}
\hline The Items of Bicycling Motivation & \multicolumn{2}{c}{ Component } \\
\cline { 2 - 3 } & Other Motivations & Convenient \\
\hline Bicycling can improve health & 0.817 & \\
Bicycling can protect the environment & 0.809 & \\
Bicycling can save money & 0.666 & 0.653 \\
It is easier to park a bicycle & 0.639 & 0.795 \\
Bicycling can avoid traffic jams & 0.614 & 20.584 \\
I cycle for fun & & 59.445 \\
Bicycling is faster & 38.862 & 1.647 \\
Bicycling is convenient & 38.862 & 3.109 \\
\% of Variance & & \\
Cumulative \% & & \\
Eigenvalues &
\end{tabular}

Extraction Method: Principal Component Analysis. Rotation Method: Varimax with Kaiser Normalization.

\subsection{Multivariate Models of the Acceptable Bicycling Distance}

The multivariate models of the acceptable bicycling distance of rural residents comprise all the previously described independent variables. Multiple linear regression was estimated using NLOGIT 5.0. (Econometric Software, Plainview, NY, USA) Table 7 shows the results.

Table 7 shows that the socio-demographic attributes of rural residents do not significantly affect their acceptable bicycling distance, except for age, which negatively affects their acceptable bicycling distance. This result is inconsistent with the conclusions of the majority of the existing relevant empirical studies. Moreover, the majority of the related studies have shown that socio-demographic attributes often have more significant effects on bicycling behavior than other variables [12,64]. This finding is significantly related to the fact that there is no fixed income for the left-behind population in rural areas in Sichuan and that the left-behind population members are generally older, young, or female-dominated. The following subsections mainly analyze the impact of the individual bicycling psychology and rural built environment on the acceptable bicycling distance of rural residents. 
Table 7. Multiple linear regression results of the acceptable bicycling distance.

\begin{tabular}{|c|c|c|c|c|}
\hline \multirow[b]{2}{*}{ Variables } & \multicolumn{2}{|c|}{ Original Linear Regression } & \multicolumn{2}{|c|}{$\begin{array}{l}\text { The Result of Linear Regression } \\
\text { without Insignificant Variables }\end{array}$} \\
\hline & Coef. & $p$-Value & Coef. & $p$-Value \\
\hline Constant & $2.494^{* * *}$ & 0.000 & $2.615^{* * *}$ & 0.000 \\
\hline Male & 0.071 & 0.362 & & \\
\hline Age & -0.033 & 0.279 & & \\
\hline Income & -0.007 & 0.751 & & \\
\hline Cycling ancillary facilities & -0.018 & 0.636 & & \\
\hline Bicycle lane conditions & 0.034 & 0.363 & & \\
\hline Safety & $0.170^{* * *}$ & 0.000 & $0.171^{* * *}$ & 0.000 \\
\hline Other motivations & 0.043 & 0.287 & & \\
\hline Convenient & $-0.084^{* *}$ & 0.026 & $-0.080^{* *}$ & 0.049 \\
\hline Physical activate & $0.395^{* * *}$ & 0.000 & $0.398^{* * *}$ & 0.000 \\
\hline Go to work/school & $0.293^{* * *}$ & 0.003 & $0.281^{* * *}$ & 0.009 \\
\hline Bike with children & -0.083 & 0.433 & & \\
\hline Go shopping & $-0.528^{* * *}$ & 0.000 & $-0.542^{* * *}$ & 0.000 \\
\hline Visit friends & $0.192 * *$ & 0.029 & 0.113 & 0.233 \\
\hline To entertainment & 0.005 & 0.963 & & \\
\hline Others & $-0.318^{* * *}$ & 0.003 & $-.340^{* * *}$ & 0.004 \\
\hline Liking riding motorcycles & $0.084^{* * *}$ & 0.010 & $0.116^{* * *}$ & 0.010 \\
\hline Liking riding electric bicycles & $-0.083^{* *}$ & 0.011 & -0.073 & 0.186 \\
\hline Liking bicycling & $0.167^{* * *}$ & 0.000 & 0.054 & 0.322 \\
\hline O_P (Table 3) & $0.098^{* *}$ & 0.019 & $0.144^{* * *}$ & 0.000 \\
\hline O_M (Table 3) & -0.063 & 0.210 & & \\
\hline O_S (Table 3) & -0.056 & 0.261 & & \\
\hline O_H (Table 3) & $0.139^{* * *}$ & 0.000 & $0.125^{* *}$ & 0.011 \\
\hline P_S (Table 3) & 0.056 & 0.352 & & \\
\hline P_M (Table 3) & 0.029 & 0.677 & & \\
\hline P_P (Table 3) & $-0.139 * * *$ & 0.002 & $-0.117^{* * *}$ & 0.001 \\
\hline P_H (Table 3) & 0.015 & 0.770 & & \\
\hline $\begin{array}{c}\text { Rho-squared } \\
\left(\mathrm{R}^{2}=1-(\mathrm{L}(\beta) / \mathrm{L}(\mathrm{c}))\right)\end{array}$ & \multicolumn{2}{|c|}{0.274} & \multicolumn{2}{|c|}{0.243} \\
\hline Number of observations & \multicolumn{2}{|c|}{374} & \multicolumn{2}{|c|}{374} \\
\hline
\end{tabular}

** Significant at the $5 \%$ level. ${ }^{* * *}$ Significant at the $1 \%$ level.

\subsubsection{Influence of the Psychological Factors of Bicycling on the Acceptable Bicycling Distance}

Table 7 shows that the individual psychological factors of bicycling of each respondent significantly affect the acceptable bicycling distance of rural residents. Safety attitude (i.e., third common factor) on bicycling infrastructure conditions has a significant and positive influence on the acceptable bicycling distance of rural residents. This result notes that small motor vehicle traffic, dedicated separate bicycle lanes, and secure bicycle parking lot at the destination can significantly encourage rural residents to accept long bicycling distances. Note that $75.67 \%$ of the respondents believe that the good quality of the route surface can encourage them to ride a bicycle. However, this infrastructure does not significantly affect the acceptable bicycling distance. That is, the bicycling infrastructure conditions that meet the requirement to choose bicycles and acceptable longer bicycling distance are not precisely the same. The special separate bicycle lane can encourage rural residents to choose bicycles but also satisfy their requirement for long bicycling distances.

For bicycling motivation, the second common factor (i.e., convenience) significantly influences the acceptable bicycling distance of rural residents. In particular, rural residents who believe that bicycling is convenient and fast are reluctant to ride long distances. Instead, they believe that short-distance travel can better reflect the convenience brought by bicycles. Thus, people who think that bicycles are convenient and fast may ride bicycles frequently. This conclusion indirectly coincides with the conclusion of Fu and Farber on bicycling frequency [12]. Although $83.43 \%$ of the rural residents believe 
that bicycling can enhance physical fitness, this bicycling motivation does not significantly affect their acceptable bicycling distance. Similar bicycling motivations include protecting the environment and saving money. Therefore, motivation and specific behavior are not constantly consistent [65].

For bicycling purposes, five of the seven indicators significantly affect the acceptable bicycling distance. Among the indicators of bicycling purpose, physical activity had a significant and positive influence on the acceptable bicycling distance of rural residents, with the largest impact coefficient among all the influencing factors. However, only $10.70 \%$ of all the respondents selected physical activity as their bicycling purpose. That is, only a few residents in the rural areas of Sichuan are bicycling for physical activity. However, if the respondents selected physical activity as their bicycling purpose, then they would accept long bicycling distance. Fu and Farber [12] studied urban residents and showed that $79.55 \%$ of the respondents ride bicycles for physical activity, although this endeavor did not significantly affect their bicycling frequency. Thus, the two similar research results indicate that the influence of bicycling purpose on bicycling behavior is indirectly related to the number of respondents who select this bicycling purpose option. Moreover, bicycling to work and school and visiting friends has significant and positive effects on acceptable bicycling distances compared with daily shopping and other purposes of transportation. This aspect reflects the current status of the daily destination distances of rural residents. Typically, workplaces, schools, and relatives and friends are not close to home. For the purpose of these trips, the acceptable bicycling distance is relatively distant (subconsciously). Other daily trips, such as shopping, are often selected at a nearby market or the nearest convenience store. Hence, the acceptable bicycling distance is considerably short.

For riding preferences, this study mainly considers the influence of the likeness of bicycles, motorcycles, and electric bicycles on the acceptable bicycling distance of rural residents. The research results (see Table 7) show that all indicators of the riding preference have a significant impact on the acceptable bicycling distance of rural residents. This result indicates that liking bicycling is the most important factor in explaining bicycle ownership and use [49]. Moreover, liking bicycling is closely related to acceptable bicycling distance $[49,50]$. The indicators of liking riding a bicycle and motorcycle positively affect the acceptable bicycling distance of rural residents, with liking riding a bicycle having a considerable impact. Thus, rural residents who like bicycling can accept long bicycling distances. Furthermore, those who like to ride motorcycles can accept relatively long bicycling distances. By contrast, rural residents who like riding electric bicycles would accept short bicycling distances. This research conclusion completely illustrates the complementarity of bicycles and motorcycles for travel and the mutual replacement of bicycles and electric bicycles [63].

\subsubsection{Influence of the Rural Built Environment on Acceptable Bicycling Distance}

Table 7 shows that two of the four objective built environment indicators significantly influence the acceptable bicycling distance of rural residents. The distance from the village center to the nearest health center $\left(\mathrm{O}_{-} \mathrm{H}\right)$ and public transportation station $\left(\mathrm{O} \_\mathrm{P}\right)$ has a significant and positive influence on the acceptable bicycling distance of rural residents. That is, the distance between the two locations has a substantial influence. Moreover, the distance from the village center to the nearest school has a significant negative impact on the acceptable bicycling distance. Note that the authors of this study perceive that the market is a trading center in the rural areas of Sichuan and should significantly influence the bicycling behavior of rural residents. However, the market is not significant in this study. The indicators of the perceived built environment of the rural residents have limited impact on their acceptable bicycling distance. Only the perceived convenience to public transportation station significantly and negatively affects the acceptable bicycling distance. This result indicates that rural residents who believe in the convenience of going to public transport stations will accept short bicycling distances. This result is consistent with our expectations.

This study compares the influences of the objective and perceived built environment on acceptable bicycling distance of rural residents and determines that only the perceived and objective health center built environment indicator significantly influences the acceptable bicycling distance of rural residents. 
However, the effects are opposite. This result shows that the objective and perceived built environment have relatively independent effects on the acceptable bicycling distance of rural residents. Moreover, this result is consistent with that of [2] on bicycle frequency.

The multiple regression model was used to explore the socio-demographic attributes, individual bicycling psychological factors, and rural built environments on the acceptable bicycling distance of rural residents. The R-squared of the linear regression is 0.274 and the significance of the F-test of the model is 0.000 . Therefore, the model rejects the null hypothesis (all parameters are zero). Moreover, this study re-estimated the linear regression model by dropping out the insignificant variables and the results are similar to the initial model (see Table 7). Therefore, the results are consistent with our assumptions and this study adopt the original model to interpret the relationship between dependent and independent variables for more information. The influence of the individual bicycling psychological factors of rural residents on their acceptable bicycling distance is significant, followed by the built environment indicators, whereas the impact of social demographic characteristics is limited. However, the socio-demographic characteristics in the relevant research literature significantly affect travel behavior $[2,12,63]$. This finding may be related to the characteristics of the left-behind population in rural Sichuan.

\section{Strengths and Limitations}

Given that this study is the first on the bicycling behavior of rural residents in Sichuan, the current research completely considers the impact of the individual bicycling psychological factors on the acceptable bicycling distances of rural residents. This research also compares and analyzes the influences of the objective and perceived built environment of rural residents on their acceptable bicycling distances. Thus, the current study substantially contributes in explaining the bicycling behavior (i.e., acceptable bicycling distance) in rural Sichuan (i.e., undeveloped areas). Moreover, this study deployed two multivariate models to accurately fit the relationships between variables. Accordingly, the results are consistent.

This study has two limitations. First, cross-sectional data were used without considering the impact of changes on the rural built environment and the psychological determinants of rural residents on the acceptable bicycling distance. Second, the aggregate data of the objective built environment in rural areas used in this study (i.e., distance from the village center to various destinations) do not specify the distance from each sample family to various destinations. Therefore, accurately obtaining the inner link between the objective and perceived built environment is virtually impossible. This finding is mainly the result of lack of rural geographic information data. Thus, additional research in the future is recommended.

\section{Conclusions and Policy Implications}

An increasing number of studies have focused on bicycling frequency and choice for residents in large cities. The number of rural household bicycles has continued to decline owing to rapid urbanization and new rural construction in China. In all modes of travel, the proportion of bicycling is the lowest. The current study uses face-to-face questionnaire survey and on-site measurement data to analyze the impact of individual bicycling psychology and built environment on the acceptable bicycling distance of rural residents. The purpose of this research is to provide a theoretical basis for the ecological construction of new rural areas in China and encourage low-carbon travel for rural residents.

The results suggest that further investment in the construction of special bicycle lanes is needed to provide efficient road infrastructure for rural residents, thereby encouraging them to choose the bicycle mode and bicycle use. Moreover, separating bike lanes from motor vehicle lanes reduces motor vehicle traffic. The perceived convenience and speed of rural residents for bicycling will encourage them to travel short distances. Therefore, daily destinations, such as grocery stores, shops, and markets, should be completely considered within the range of the acceptable bicycling distances of rural residents (e.g., the average acceptable bicycling distance is $2.873 \mathrm{~km}$; see Figure 4). The riding preference of rural 
residents significantly affects their acceptable bicycling distance. Therefore, local governments should increase the provision of information on the advantages of bicycling, such as benefits to physical and mental health, zero carbon emissions, and environmental protection, to stimulate rural residents to like bicycling. To address the bicycling requirements of rural residents, local governments and provincial agencies planning the construction of new rural areas should consider the impact of objective rural infrastructure and perceived built environment on the travel behavior of rural residents.

Author Contributions: All authors contributed to the research presented in this paper. Y.W., Y.A., and Y.Z. had the original idea for the study; the co-authors conceived and designed the questionnaire. Y.A. and Y.W. organized the investigation; Y.A. analyzed the data and drafted the manuscript, which was revised by Y.L., L.Z., and Y.C. All authors have read and approved the final manuscript.

Funding: The authors appreciate financial support from the Natural Science Key Project from the Sichuan Provincial Department of Education (18ZA0048), Sichuan Rural Community Governance Research Center funding (SQZL2019C01), Sichuan Xinnong Village Wind Civilization Construction Research Center funding (SCXN2019-004), and the Development Research Center of Oil and Gas, Sichuan (CYQK-SKB17-04).

Conflicts of Interest: The authors declare no conflict of interest.

\section{References}

1. Götschi, T.; Castro, A.; Deforth, M.; Miranda-Moreno, L.; Zangenehpour, S. Towards a comprehensive safety evaluation of cycling infrastructure including objective and subjective measures. J. Transp. Health 2018, 8, 44-54. [CrossRef]

2. Ma, L.; Dill, J. Associations between the objective and perceived built environment and bicycling for transportation. J. Transp. Health 2015, 2, 248-255. [CrossRef]

3. Sallis, J.F.; Frank, L.D.; Saelens, B.E.; Kraft, M.K. Active transportation and physical activity: Opportunities for collaboration on transportation and public opportunities health research. Transp. Res. Part A Policy Pract. 2004, 38, 249-268. [CrossRef]

4. Moore, S.C.; Lee, I.M.; Weiderpass, E.; Campbell, P.T.; Sampson, J.N.; Kitahara, C.M.; Keadle, S.K.; Arem, H.; De Gonzalez, A.B.; Hartge, P.; et al. Association of Leisure-Time Physical Activity With Risk of 26 Types of Cancer in 1.44 Million Adults. JAMA Intern Med. 2016, 176, 816-825. [CrossRef] [PubMed]

5. Nocon, M.; Hiemann, T.; Mueller-Riemenschneider, F.; Thalau, F.; Roll, S.; Willich, S.N. Association of physical activity with all-cause and cardiovascular mortality: A systematic review and meta-analysis. Eur. J. Cardiov. Prev. R 2008, 15, 239-246. [CrossRef] [PubMed]

6. Berrigan, D.; Troiano, R.P.; McNeel, T.; DiSogra, C.; Ballard-Barbash, R. Active transportation increases adherence to activity recommendations. Am. J. Prev. Med. 2006, 31, 210-216. [CrossRef] [PubMed]

7. De Geus, B.; De Smet, S.; Nijs, J.; Meeusen, R. Determining the intensity and energy expenditure during commuter cycling. Br. J. Sport Med. 2007, 41, 8-12. [CrossRef] [PubMed]

8. Dill, J. Bicycling for Transportation and Health: The Role of Infrastructure. J. Public Health Policy 2009, 30, S95-S110. [CrossRef]

9. Haskell, W.L. General dose response issues concerning physical activity and health. Health Enhancing Phys. Act. 2004, 6, 149-168.

10. Titze, S.; Stronegger, W.J.; Janschitz, S.; Oja, P. Association of built-environment, social-environment and personal factors with bicycling as a mode of transportation among Austrian city dwellers. Prev. Med. 2008, 47, 252-259. [CrossRef]

11. Gatersleben, B.; Appleton, K.M. Contemplating cycling to work: Attitudes and perceptions in different stages of change. Transp. Res. Part A Policy Pract. 2007, 41, 302-312. [CrossRef]

12. Fu, L.; Farber, S. Bicycling frequency: A study of preferences and travel behavior in Salt Lake City Utah. Transp. Res. Part A Policy Pract. 2017, 101, 30-50. [CrossRef]

13. Handy, S.L.; Xing, Y. Factors Correlated with Bicycle Commuting: A Study in Six Small, U.S. Cities. Int. J. Sustain. Transp. 2011, 5, 91-110. [CrossRef]

14. Parkin, J.; Wardman, M.; Page, M. Models of perceived cycling risk and route acceptability. Accid. Anal. Prev. 2007, 39, 364-371. [CrossRef] [PubMed]

15. Handy, S.; McCann, B. The Regional Response to Federal Funding for Bicycle and Pedestrian Projects. J. Am. Plan. Assoc. 2011, 77, 23-38. [CrossRef] 
16. Bonham, J.; Koth, B. Universities and the cycling culture. Transp. Res. Part D Transp. Environ. 2010, 15, 94-102. [CrossRef]

17. Shaheen, S.A.; Guzman, S.; Zhang, H. Bikesharing in Europe, the Americas, and Asia Past, Present, and Future. Transp. Res. Rec. 2010, 2143, 159-167. [CrossRef]

18. Heinen, E.; van Wee, B.; Maat, K. Commuting by Bicycle: An Overview of the Literature. Transp. Rev. 2010, 30, 59-96. [CrossRef]

19. Pucher, J.; Dill, J.; Handy, S. Infrastructure, programs, and policies to increase bicycling: An international review. Prev. Med. 2010, 50, S106-S125. [CrossRef]

20. Yang, L.; Sahlqvist, S.; McMinn, A.; Griffin, S.J.; Ogilvie, D. Interventions to promote cycling: systematic review. Br. Med. J. 2010, 341. [CrossRef]

21. National Bureau of Statistics of the People's Republic of China. China Statistical Yearbook 1986-2017; National Bureau of Statistics of the People's Republic of China: Beijing, China.

22. Foster, C.E.; Panter, J.R.; Wareham, N.J. Assessing the impact of road traffic on cycling for leisure and cycling to work. Int. J. Behav. Nutr. Phys. Act. 2011, 8. [CrossRef] [PubMed]

23. Sallis, J.F.; Conway, T.L.; Dillon, L.I.; Frank, L.D.; Adams, M.A.; Cain, K.L.; Saelens, B.E. Environmental and demographic correlates of bicycling. Prev. Med. 2013, 57, 456-460. [CrossRef] [PubMed]

24. Chataway, E.S.; Kaplan, S.; Nielsen, T.A.S.; Prato, C.G. Safety perceptions and reported behavior related to cycling in mixed traffic: A comparison between Brisbane and Copenhagen. Transp. Res. Part F Traffic Psychol. Behav. 2014, 23, 32-43. [CrossRef]

25. Thomas, B.; DeRobertis, M. The safety of urban cycle tracks: A review of the literature. Accid. Anal. Prev. 2013, 52, 219-227. [CrossRef] [PubMed]

26. Daley, M.; Rissel, C. Perspectives and images of cycling as a barrier or facilitator of cycling. Transp. Policy 2011, 18, 211-216. [CrossRef]

27. Fishman, E.; Washington, S.; Haworth, N. Barriers and facilitators to public bicycle scheme use: A qualitative approach. Transp. Res. Part F Traffic Psychol. Behav. 2012, 15, 686-698. [CrossRef]

28. Handy, S. Critical Assessment of the Literature on the Relationships among Transportation, Land Use, and Physical Activity; Transportation Research Board and the Institute of Medicine Committee on Physical Activity, Health, Transportation, and Land Use Resource Paper for TRB Special Report: Washington, DC, USA, 2005; Volume 282, pp. 1-81.

29. Willis, D.P.; Manaugh, K.; El-Geneidy, A. Cycling Under Influence: Summarizing the Influence of Perceptions, Attitudes, Habits, and Social Environments on Cycling for Transportation. Int. J. Sustain. Transp. 2015, 9 , 565-579. [CrossRef]

30. Fernández-Heredia, Á.; Monzón, A.; Jara-Díaz, S. Understanding cyclists' perceptions, keys for a successful bicycle promotion. Transp. Res. Part A Policy Pract. 2014, 63, 1-11. [CrossRef]

31. Timperio, A.; Ball, K.; Salmon, J.; Roberts, R.; Giles-Corti, B.; Simmons, D.; Baur, L.A.; Crawford, D. Personal, family, social, and environmental correlates of active commuting to school. Am. J. Prev. Med. 2006, 30, 45-51. [CrossRef]

32. Heinen, E.; Maat, K.; van Wee, B. The role of attitudes toward characteristics of bicycle commuting on the choice to cycle to work over various distances. Transp. Res. Part D-Traffic Environ. 2011, 16, 102-109. [CrossRef]

33. Stinson, M.A.; Bhat, C.R. Commuter bicyclist route choice-Analysis using a stated preference survey. Pedestr. Bicycl. 2003, 1828, 107-115. [CrossRef]

34. Pucher, J.; Buehler, R. Making cycling irresistible: Lessons from the Netherlands, Denmark and Germany. Transp. Rev. 2008, 28, 495-528. [CrossRef]

35. Beenackers, M.A.; Foster, S.; Kamphuis, C.B.M.; Titze, S.; Divitini, M.; Knuiman, M.; van Lenthe, F.J.; Giles-Corti, B. Taking Up Cycling After Residential Relocation Built Environment Factors. Am. J. Prev. Med. 2012, 42, 610-615. [CrossRef] [PubMed]

36. Parkin, J.; Wardman, M.; Page, M. Estimation of the determinants of bicycle mode share for the journey to work using census data. Transportation 2008, 35, 93-109. [CrossRef]

37. Kerr, J.; Emond, J.A.; Badland, H.; Reis, R.; Sarmiento, O.; Carlson, J.; Sallis, J.F.; Cerin, E.; Cain, K.; Conway, T.; et al. Perceived Neighborhood Environmental Attributes Associated with Walking and Cycling for Transport among Adult Residents of 17 Cities in 12 Countries: The IPEN Study. Environ. Health Perspect 2016, 124, 290-298. [CrossRef] [PubMed] 
38. Saelens, B.E.; Sallis, J.F.; Frank, L.D. Environmental correlates of walking and cycling: Findings from the transportation, urban design, and planning literatures. Ann. Behav. Med. 2003, 25, 80-91. [CrossRef] [PubMed]

39. Sener, I.N.; Eluru, N.; Bhat, C.R. An analysis of bicycle route choice preferences in Texas, US. Transportation 2009, 36, 511-539. [CrossRef]

40. Broach, J.; Dill, J.; Gliebe, J. Where do cyclists ride? A route choice model developed with revealed preference GPS data. Transp. Res. Part A Policy Pract. 2012, 46, 1730-1740. [CrossRef]

41. Thakuriah, P.; Metaxatos, P.; Lin, J.N.; Jensen, E. An examination of factors affecting propensities to use bicycle and pedestrian facilities in suburban locations. Transp. Res. Part D Traffic Environ. 2012, 17, 341-348. [CrossRef]

42. Van Acker, V.; Derudder, B.; Witlox, F. Why people use their cars while the built environment imposes cycling. J. Transp. Land Use 2013, 6, 53-62. [CrossRef]

43. Van Dyck, D.; Veitch, J.; De Bourdeaudhuij, I.; Thornton, L.; Ball, K. Environmental perceptions as mediators of the relationship between the objective built environment and walking among socio-economically disadvantaged women. Int. J. Behav. Nutr. Phys. Act. 2013, 10. [CrossRef] [PubMed]

44. Gebel, K.; Bauman, A.E.; Sugiyama, T.; Owen, N. Mismatch between perceived and objectively assessed neighborhood walkability attributes: Prospective relationships with walking and weight gain. Health Place 2011, 17, 519-524. [CrossRef] [PubMed]

45. Rodriguez, D.A.; Evenson, K.R.; Roux, A.V.D.; Brines, S.J. Land Use, Residential Density, and Walking The Multi-Ethnic Study of Atherosclerosis. Am. J. Prev. Med. 2009, 37, 397-404. [CrossRef] [PubMed]

46. Brownson, R.C.; Hoehner, C.M.; Day, K.; Forsyth, A.; Sallis, J.F. Measuring the Built Environment for Physical Activity State of the Science. Am. J. Prev. Med. 2009, 36, S99-S123. [CrossRef] [PubMed]

47. Ewing, R.; Handy, S. Measuring the unmeasurable: Urban design qualities related to walkability. J. Urban Des. 2009, 14, 65-84. [CrossRef]

48. Elvik, R.; Bjornskau, T. How accurately does the public perceive differences in transport risks? An exploratory analysis of scales representing perceived risk. Accid. Anal. Prev. 2005, 37, 1005-1011. [CrossRef] [PubMed]

49. Handy, S.L.; Xing, Y.; Buehler, T.J. Factors associated with bicycle ownership and use: a study of six small U.S. cities. Transportation 2010, 37, 967-985. [CrossRef]

50. Xing, Y.; Handy, S.L.; Mokhtarian, P.L. Factors associated with proportions and miles of bicycling for transportation and recreation in six small US cities. Transp. Res. Part D Traffic Environ. 2010, 15, 73-81. [CrossRef]

51. Hong, J.; Shen, Q. Residential density and transportation emissions: examining the connection by addressing spatial autocorrelation and self-selection. Transp. Res. Part D Transp. Environ. 2013, 22, 75-79. [CrossRef]

52. Cao, X.Y. Examining the impacts of neighborhood design and residential self-selection on active travel: a methodological assessment. Urban Geogr. 2015, 36, 236-255. [CrossRef]

53. Cao, X.Y. Examining the Relationship Between Neighborhood Built Environment and Travel Behavior: A Review from the US Perspective. Urban Plan. Int. 2015, 30, 46-52.

54. Garrard, J.; Rose, G.; Lo, S.K. Promoting transportation cycling for women: The role of bicycle infrastructure. Prev. Med. 2008, 46, 55-59. [CrossRef] [PubMed]

55. Akar, G.; Fischer, N.; Namgung, M. Bicycling Choice and Gender Case Study: The Ohio State University. Int. J. Sustain. Transp. 2013, 7, 347-365. [CrossRef]

56. Wang, J.Y.; Mirza, L.; Cheung, A.K.; Moradi, S. Transforming Auckland into a Bicyclefriendly City: Understanding Factors Influencing Choices of Cyclists and Potential Cyclists; Australasian Transport Research Forum: Perth, Australia, 2012.

57. Pucher, J.; Renne, J.L. Socioeconomics of urban travel: Evidence from the 2001 NHTS. Transp. Q. 2003, 57, $49-77$.

58. Krizek, K.J.; Johnson, P.J. Proximity to trails and retail: Effects on urban cycling and walking. J. Am. Plan. Assoc. 2006, 72, 33-42. [CrossRef]

59. Damant-Sirois, G.; Grimsrud, M.; El-Geneidy, A.M. What's your type: a multidimensional cyclist typology. Transportation 2014, 41, 1153-1169. [CrossRef]

60. Kuzmyak, J.R.; Walters, J.; Bradley, M.; Kockelman, K.M. Estimating Bicycling and Walking for Planning and Project Development: A Guidebook; Transportation Research Board: Washington, DC, USA, 2014.

61. Greene, W.H. Econometric Analysis; Pearson Education India: Delhi, India, 2003. 
62. Ao, Y.; Yang, D.; Chen, C.; Wang, Y. Exploring the effects of the rural built environment on household car ownership after controlling for preference and attitude: Evidence from Sichuan, China. J. Transp. Geogr. 2019, 74, 24-36. [CrossRef]

63. Ao, Y.; Chen, C.; Yang, D.; Wang, Y. Relationship between Rural Built Environment and Household Vehicle Ownership: An Empirical Analysis in Rural Sichuan, China. Sustainability 2018, 10, 1566. [CrossRef]

64. Msambichaka, B.; Abdul, R.; Abdulla, S.; Klatser, P.; Tanner, M.; Kaushik, R.; Bringolf-Isler, B.; Geubbels, E.; Eze, I.C. A Cross-Sectional Examination of Physical Activity Levels and Their Socio-Demographic Determinants in Southern Tanzania. Int. J. Environ. Res. Public Health 2018, 15, 1054. [CrossRef]

65. Xing, Y.; Volker, J.; Handy, S. Why do people like bicycling? Modeling affect toward bicycling. Transp. Res. Part F Traffic Psychol. Behav. 2018, 56, 22-32. [CrossRef]

(C) 2019 by the authors. Licensee MDPI, Basel, Switzerland. This article is an open access article distributed under the terms and conditions of the Creative Commons Attribution (CC BY) license (http://creativecommons.org/licenses/by/4.0/). 